\title{
Regular physical activity levels and incidence of restrictive spirometry pattern: a longitudinal analysis of two population-based cohorts
}

Anne-Elie Carsin, Dirk Keidel, Elaine Fuertes, Medea Imboden, Joost Weyler, Dennis

Nowak, Joachim Heinrich, Silvia Pascual Erquicia, Jesus Martinez-Moratalla, Ismael

Huerta, Jose-Luis Sanchez, Emmanuel Schaffner, Seraina Caviezel, Anna Beckmeyer-

Borowko, Chantal Raherison, Isabelle Pin, Pascal Demoly, Bénédicte Leynaert, Isa

Cerveri, Guilia Squillacioti, Simone Accordini, Thorarinn Gislason, Cecilie Svanes,

Kjell Toren, Bertill Forsberg, Christer Janson, Rain Jogi, Margareta Emtner, Francisco

Gómez Real, Debbie Jarvis, Stefano Guerra, Shyamali C Dharmage, Nicole Probst-

Hensch, and Judith Garcia-Aymerich

Correspondence to Dr. Judith Garcia Aymerich, Barcelona Institute of Global Health

(ISGlobal), Doctor Aiguader 88, 08003 Barcelona, Spain, (e-mail: judith.garcia@isglobal.org)

Editorial queries should be addressed to Ms. Anne-Elie Carsin, Barcelona Institute of Global Health (ISGlobal), Doctor Aiguader 88, 08003 Barcelona, Spain, (e-mail: anneelie.carsin@isglobal.org, phone:+34 93227 1806)

Author affiliations: ISGlobal, Barcelona, Spain (Anne-Elie Carsin, Stefano Guerra, and Judith Garcia-Aymerich); IMIM-Hospital del Mar, Barcelona, Spain (Anne-Elie Carsin); CIBER Epidemiologia y Salud Publica, Barcelona, Spain (Anne-Elie Carsin and Judith Garcia-Aymerich); Universitat Pompeu Fabra (UPF), Barcelona, Spain (Anne-Elie Carsin and Judith Garcia-Aymerich); Epidemiology and Public Health, Swiss Tropical and Public Health Institute, Basel, Switzerland (Dirk Keidel, Medea Imboden, Emmanuel Schaffner, Seraina Caviezel, Anna Beckmeyer-Borowko, and 
Nicole Probst-Hensch); University of Basel, Switzerland (Dirk Keidel, Medea Imboden, Emmanuel Schaffner, Seraina Caviezel, Anna Beckmeyer-Borowko, and Nicole ProbstHensch); National Heart and Lung Institute, Imperial College London, United Kingdom (Elaine Fuertes and Debbie Jarvis); Department of Epidemiology and Social Medicine, Faculty of Medicine and Health Sciences, Belgium (Joost Weyler); Institute and Clinic for Occupational, Social and Environmental Medicine, LMU Munich, Germany (Dennis Nowak and Joachim Heinrich); Respiratory Department, Galdakao Hospital, OSI Barrualde-Galdakao, Biscay, Spain (Silvia Pascual Erquicia); Complejo Hospitalario Universitario de Albacete, Spain (Jesus Martinez-Moratalla); Epidemiological Surveillance Section, Directorate General of Public Health, Oviedo, Spain (Ismael Huerta);University Hospital of Huelva, Spain (José-Luis Sanchez); Department of Psychosomatic, University Hospital Basel, Switzerland (Seraina Caviezel); Université de Bordeaux, Inserm, UMR 1219, France (Chantal Raherison); CHU de Grenoble Alpes, Inserm, U1209, IAB, Grenoble, France (Isabelle Pin); University Hospital of Montpellier and Inserm UMRS-1136, France (Pascal Demoly); Inserm, UMR 1152, Pathophysiology and Epidemiology of Respiratory Diseases, Paris, France (Bénédicte Leynaert); Istituto di Ricovero e Cura a Carattere Scientifico San Matteo Hospital Foundation, University of Pavia, Italy (Isa Cerveri); Department of Public Health and Pediatrics, University of Turin, Italy (Guilia Squillacioti); Unit of Epidemiology and Medical Statistics, Department of Diagnostics and Public Health, University of Verona, Verona, Italy (Simone Accordini); Landspitali University Hospital, Reykjavik, Iceland (Thorarinn Gislason); Medical Faculty, University of Iceland, Reykjavik Iceland (Thorarinn Gislason); Centre for International Health, University of Bergen, Norway (Cecilie Svanes); Department of Occupational Medicine, Haukeland University Hospital, Bergen, Norway (Cecilie Svanes); Occupational and 
environmental medicine, Department of Public Health and Community Medicine, Sahlgrenska Academy, Gothenburgn (Kjell Toren); Department of Public Health and Clinical Medicine, Umeå University, Sweden (Bertill Forsberg); Department of Medical Sciences, Respiratory, Allergy and Sleep Research, Uppsala University, Sweden (Christer Janson and Margareta Emtner); Lung Clinic, Tartu University Clinics, Estonia (Rain Jogi); Haukeland University Hospital, Bergen, Norway (Francisco Gómez Real); MRC-PHE Centre for Environment and Health, Imperial College London, United Kingdom (Debbie Jarvis); Asthma and Airway Disease Research Center, University of Arizona, Tucson, Arizona (Stefano Guerra); Centre for Epidemiology and Biostatistics, University of Melbourne, Australia (Shyamali C Dharmage).

Funding information This work was supported by the Ageing Lungs in European Cohorts (ALEC) Study (www.alecstudy.org), which has received funding from the European Union's Horizon 2020 research and innovation programme under grant agreement No. 633212. The funding agencies for the European Community Respiratory Health Survey (ECRHS II and ECRHS III) are reported in the Web Appendix 1. SAPALDIA is funded by the National Science Foundation Grant Nr. 33CS30-177506. ISGlobal is a member of CERCA Programme/Generalitat de Catalunya. The funding sources had no involvement in the study design, the collection, analysis and interpretation of data or in the writing of the report and in the decision to submit the article for publication.

Conflict of interest: none declared.

Running head: Physical activity and restrictive spirometry pattern 


\begin{abstract}
A restrictive spirometry pattern is associated with high morbidity and mortality. Whether practicing regular physical activity protects against this pattern has never been studied. We estimated the association between regular physical activity and the incidence of restrictive spirometry pattern. Forced expiratory volume in 1 second, forced vital capacity (FVC) and physical activity were assessed between 2000-2002 in the ECRHS ( $n=2,757,39-67$ years) and SAPALDIA $(n=2,610,36-82$ years) populationbased European cohorts, and again approximately 10-years later (2010-2013). Subjects with restrictive or obstructive spirometry pattern at baseline were excluded. We assessed the association of being active at baseline (defined as being physically active $\geq 2-3$ times/wk for $\geq 1 \mathrm{~h}$ ) with restrictive spirometry pattern at follow-up (defined as a post-bronchodilator forced expiratory volume in 1 second /FVC ratio $\geq$ Lower Limit of Normal and FVC $<80 \%$ predicted) using modified Poisson regression, adjusting for relevant confounders. After 10 years of follow-up, 3.3\% of participants had developed restrictive spirometry pattern. Being physically active was associated with a lower risk of developing this phenotype (Relative Risk $=0.76,95 \%$ Confidence Interval $=0.59$ 0.98). This association was stronger among those overweight and obese, compared to those with normal weight $\left(P_{\text {interaction }}=0.06\right)$. In two large European studies, adults practicing regular physical activity were at lower risk of developing restrictive spirometry pattern after 10 years.
\end{abstract}

Keywords: Physical activity, spirometry, restrictive spirometry, BMI, FVC 


\section{Abbreviations:}

FVC: forced vital capacity, $\mathrm{FEV}_{1}$ : forced expiratory volume in the first second, ECRHS: European Community Respiratory Health Survey, SAPALDIA: Swiss study on Air Pollution and Lung and Heart Diseases in adults, BMI: Body mass index, RR: Relative Risk, CI: confidence interval 
Restrictive spirometry pattern is an under-recognised disorder associated with high morbidity and mortality (1-3). It is characterised by low forced vital capacity (FVC), with a preserved forced expiratory volume in the first second $\left(\mathrm{FEV}_{1}\right) / \mathrm{FVC}$ ratio. The prevalence of restrictive spirometry pattern varies according to the definition used, ranging between 5 and $10 \%$ in the US $(3,4)$ and Europe $(5,6)$. The determinants of restrictive spirometry pattern remain largely unknown.

We hypothesise that regular physical activity could be related to restrictive spirometry pattern incidence as physical activity has been consistently associated with higher lung function levels (7) and individuals with restrictive spirometry pattern were found to have low levels of physical activity in a cross-sectional multicenter analysis (8). The important health benefits of regular physical activity and the modifiability of this behaviour, combined with the largely unknown determinants of restrictive pattern incidence, makes this a highly relevant public health research question.

This study aimed to determine if regular physical activity was associated with the development of restrictive spirometry pattern using two population-based adult cohorts followed for 10 years.

\section{METHODS}

Study design

Longitudinal data collected from the European Community Respiratory Health Survey (ECRHS), involving 46 centres in 24 countries, and the Swiss study on Air Pollution and Lung Disease in adults (SAPALDIA), involving 8 centres in Switzerland, were used. Both studies followed a very similar protocol, using highly comparable questionnaires and procedures $(9,10)$. The current analysis used data collected during 
ECRHS II and SAPALDIA 2 (around 2000-2002) and approximately 10 years later during ECRHS III and SAPALDIA 3, hereon referred to as the baseline and follow-up examinations. Subjects lost to follow-up ( $25 \%$ of the baseline sample) were on average older and more likely to have a greater Body Mass Index (BMI), to report asthma and to be a smoker than subjects who were included, as previously published (11).

All participants with obstructive spirometry pattern at baseline or follow-up and participants with restrictive spirometry pattern at baseline (definitions below) were excluded. Written informed consent was obtained from all participants and the appropriate institutional ethics committees in each participating centre approved the study.

Variables

Lung function was assessed by spirometry according to ATS recommendations (12). Details of the spirometers used in each centre are provided elsewhere (7). At baseline, pre-bronchodilator measurements were performed. At follow-up, spirometry was performed both pre- and post-bronchodilation (15 minutes after administering two $100 \mu \mathrm{g}$ puffs of salbutamol using a spacer). We derived the percent value predicted for FVC and the Lower-Limit of Normal for the $\mathrm{FEV}_{1} / \mathrm{FVC}$ ratio using study-specific equations $(6,13)$. A restrictive spirometry pattern was defined as having a postbronchodilator $\mathrm{FEV}_{1} / \mathrm{FVC} \geq$ Lower-Limit of Normal and a $\mathrm{FVC}<80 \%$ predicted, as done previously with these population-based data (8) to maximise sample size (5). An obstructive spirometry pattern was defined as $\mathrm{FEV}_{1} / \mathrm{FVC}<$ Lower-Limit of Normal. Subjects with neither a restrictive nor an obstructive spirometry pattern were defined as having normal spirometry. 
Physical activity was assessed by questionnaire and reported at baseline. Subjects were categorized as being regularly active if they reported usual practice of vigorous physical activity 2-3 times a week or more and with a duration of about 1 hour or more, as done previously $(7,8,14)$. All other participants were defined as non-active.

Information on baseline characteristics (age, sex, education, smoking status and passive smoking), current (within the last 12 months) respiratory symptoms (asthma attack, wheezing, woken with tight chest, woken by attack of shortness of breath, woken by attack of coughing and avoiding exercise because of breathing problems), chronic respiratory symptoms (ever asthma, chronic bronchitis and chronic cough) and diagnosed chronic conditions (diabetes, depression, stroke and hypertension) of the participants was collected using questionnaires. BMI was derived using height and weight measured at baseline and follow-up and classified as normal $(<25)$, overweight $(\geq 25-30)$ and obese (30+) according to WHO classifications (15)

\section{Statistical analysis.}

As ECRHS and SAPALDIA share a very similar protocol, their recruitment was conducted at similar time-periods, and restrictive spirometry pattern incidence was comparable between studies in both genders, data were pooled to maximise statistical power. Pooling of data was further supported by the lack of differences in the obtained estimates and no evidence of heterogeneity when results were stratified by study and meta-analyzed (not shown).

We assessed the association between physical activity reported at baseline and new onset of restrictive spirometry pattern using modified Poisson regression, adjusting for 
age, sex, smoking status, potential confounders that were significantly associated with both physical activity and restrictive spirometry pattern (education, BMI, passive smoke exposure, current and chronic respiratory symptoms, and chronic conditions) and baseline FVC levels. Statistical significance was set at $P<0.05$. Centre was included as a random effect. Stratified analyses by sex, smoking, study and BMI were performed to detect possible effect modification.

The following sensitivity analyses were performed to assess the robustness of the results to assumptions about definitions, confounding and models: (1) GLI equations (16) were used to define restrictive spirometry pattern, (2) an additional adjustment for BMI change between baseline and follow-up was made, (3) asthmatics and (4) those who reported avoiding physical activity because of respiratory symptoms were excluded in separate analyses, and (5) lung function at first examination was removed as an adjustment variable. All analyses were done using Stata 14 (StataCorp, Texas, USA).

\section{RESULTS}

A total of 5,293 participants (2,714 in ECRHS and 2,579 in SAPALDIA) were available after excluding subjects with a restrictive spirometry pattern at baseline (ECRHS $n=166$, SAPALDIA $n=121$ ) and obstructive spirometry at any examination (ECRHS, $\mathrm{n}=422$, SAPALDIA, $\mathrm{n}=612)$. At follow-up, 173 (3.3\%) subjects had developed a restrictive spirometry pattern.

Table 1 shows the participant characteristics at baseline by spirometry pattern at followup. Compared to participants with normal spirometry, those with new-onset restrictive spirometry pattern were more overweight or obese at baseline $(P<0.001)$, had a higher prevalence of respiratory symptoms such as chronic cough, wheezing and waking with a 
tight chest, and hypertension, and lower levels of FEV ${ }_{1}$ and FVC (but not the $\mathrm{FEV}_{1} / \mathrm{FVC}$ ratio). Baseline characteristics according to physical activity are available in Web Table 1.

Being physically active at baseline was associated with a lower risk of having a restrictive spirometry pattern at follow-up (crude Relative Risk (RR)=0.60, 95\% confidence interval (CI) 0.46,0.79, and adjusted RR=0.76, 95\% CI 0.59,0.98, Figure 1). There was no evidence of effect modification by smoking, sex or study (Figure 1). However, analyses stratified by BMI groups suggested that the association between being active and new onset of restrictive spirometry pattern might be present only in those overweight $(\mathrm{RR}=0.43,95 \% \mathrm{CI} 0.24,0.78)$ and obese $(\mathrm{RR}=0.46,95 \% \mathrm{CI}$ $0.17,1.25)$. No association was found for normal weight subjects $(\mathrm{RR}=1.19,95 \% \mathrm{CI}$ $0.69,2.04)$. The $P_{\text {interaction }}$ between overweight/obese vs normal weight and being active was 0.06 . No substantial differences in the estimates were observed for any of the sensitivity analyses (Figure 2). However, the strength of the association was higher after removing FVC levels at baseline from the model and lower after additionally adjusting for change in BMI between the 2 examinations.

\section{DISCUSSION}

This study reveals for the first time that regular physical activity was associated with a decreased risk of developing restrictive spirometry pattern after 10-years in two longitudinal European multi-centre cohorts. This association remained after adjusting for baseline lung function and relevant confounders such as active and passive smoking and the presence of respiratory symptoms. 
Two previous cross-sectional studies have reported similar associations $(8,17)$.

Although the temporality of the observed associations could not be explored, these previous manuscripts suggested that restrictive spirometry pattern could reduce physical activity practice. Since our interest was on the association between physical activity and further restrictive spirometry pattern, we excluded all restrictive spirometry pattern cases at baseline and adjusted our analysis by baseline FVC to reduce any potential confounding of baseline lung function on physical activity (i.e. reverse causation).

Physical activity has been consistently associated with $\mathrm{FEV}_{1}$ and $\mathrm{FVC}$ levels, and less so with their decline $(7,18)$. We hypothesise that the relationship between physical activity and lung function could take on different clinical expressions (i.e., obstructive or restrictive spirometry pattern) depending on the individual distribution of health determinants, which could result in different associations between physical activity and $\mathrm{FEV}_{1}$ and FVC. Supporting this hypothesis, physical activity appears to consistently protect against developing obstructive pattern among active smokers only $(7,18)$. Since we did not observe any effect modification by smoking, we suggest that different mechanisms, than those involved in the obstructive pattern, may underlie the protective association between physical activity and the development of restrictive spirometry pattern.

Among the possible causes, restrictive spirometry pattern can be generally attributed to abnormalities, either in the lung itself (e.g., fibrosis) or outside of it (e.g., obesity, chest wall deformities), that impair one's ability to fully inflate the lungs. Thus, physical activity may exert its preventive action in relation to restrictive spirometry pattern development through mechanisms playing a role both inside and outside the lung. One 
hypothesis is that physical activity prevents weight-gain in the aging population, whose lung function is in the declining phase. Indeed, weight-gain (BMI increase) has been associated with accelerated FVC decline over 10-years in adults (19), which could result in a higher risk of incident restrictive spirometry pattern. This hypothesis is not fully supported by our study because the association between physical activity and the incidence of restrictive spirometry pattern remained after adjustment by BMI changes during follow-up. However, we acknowledge that BMI may not appropriately reflect fat mass and that fat and lean mass have different impacts on lung function (20).

Another possible mechanism could be that regular physical activity prevents systemic inflammation. Indeed physical activity has anti-inflammatory effects (21) and systemic inflammation is associated with lower lung function (22). Furthermore, subjects with restrictive spirometry pattern have elevated levels of fibrinogen and C-reactive protein $(23,24)$, two markers of inflammation. In our study, associations were strongest among those overweight and obese (who have higher systemic inflammation (25)), possibly suggesting that the anti-inflammatory effects of physical activity may be most important in this high-risk population. However, we did not observe a similar association among smokers, another group with a high inflammatory burden. Further research is warranted to confirm or refute the systemic inflammation pathway as a viable mechanism to explain our findings.

A limitation of this study is that physical activity was assessed using questionnaires, which are likely subject to non-differential misclassification. Second, some subjects were lost to follow-up and they exhibited generally worse health at baseline, which may have introduced some bias in our estimates. Third, residual confounding is possible but 
unlikely because most known relevant confounders were accounted for and unknown confounders are unlikely to account for all the observed estimate. Fourth, a single measurement of physical activity ten years prior incidence may lack precision and most likely bias our estimates towards the null. Fifth, we were unable to test whether BMI may be a mediating factor due to the small number of observed incident restrictive spirometry pattern cases. Finally, the exclusion of subjects with obstructive spirometry pattern, done to facilitate the interpretation of the results, may have lowered the statistical power because some subjects develop a mixed pattern (i.e., combination of obstructive and restrictive spirometry pattern).

Although we adjusted for baseline lung function and respiratory symptoms, we cannot exclude the possibility that reverse causation exists to some extent, for example, due to a potential association between early restrictive disease and exercise limitation leading to physical inactivity.

The strengths of the study are its longitudinal design and the combination of two large population-based cohorts with long follow-ups. Although the wide geographical distribution across Europe and the randomly selected participants make our results generalizable to diverse population subgroups, our findings should be replicated in other settings. Furthermore, high quality lung function data were available. In particular restrictive spirometry pattern was defined according to post-bronchodilator lung function measurements, which are subject to less misclassification than prebronchodilator measurements (5). The adjustment by baseline FVC to reduce reverse causation is a further strength. However, this strategy could have underestimated the magnitude of the association between physical activity and the development of 
restrictive spirometry pattern (where lower FVC levels are associated with faster decline, the so-called horse-racing effect (26)).

From a public health perspective, our study provides an important message: restrictive spirometry pattern may need to be added to the list of disorders associated with low physical activity levels. Because having a restrictive spirometry pattern is associated with poor quality of life (6) and mortality (3), if regular physical activity can truly prevent its occurrence, it may also prevent hospitalisations and deaths.

In conclusion, in a large study across Europe, being physically active was associated with a reduced risk of developing restrictive spirometry pattern after 10-years. This result reinforces the importance of promoting regular practice of physical activity in the general population to improve general health and prevent disorders later in life. 


\section{References}

1. Godfrey MS and Jankowich MD. The vital capacity is vital: epidemiology and clinical significance of the restrictive spirometry pattern. Chest. 2016;149(1):238251.

2. Scarlata S, Pedone C, Fimognari FL et al. Restrictive pulmonary dysfunction at spirometry and mortality in the elderly. Respir. Med. 2008;102(9):1349-1354.

3. Guerra S, Sherrill DL, Venker C et al. Morbidity and mortality associated with the restrictive spirometric pattern: a longitudinal study, Thorax. 2010;65(6):499-504.

4. Kurth L and Hnizdo E. Change in prevalence of restrictive lung impairment in the U.S. population and associated risk factors: the National Health and Nutrition Examination Survey (NHANES) 1988-1994 and 2007-2010. Multidiscip. Respir. Med. 2015;10(1):7.

5. Backman H, Eriksson B, Hedman L et al. Restrictive spirometric pattern in the general adult population: methods of defining the condition and consequences on prevalence. Respir. Med. 2016;120:116-123.

6. Guerra S, Carsin AE, Keidel D et al. Health-related quality of life and risk factors associated with spirometric restriction. Eur. Respir. J. 2017;49(5).

7. Fuertes E, Carsin A-E, Antó J.M. et al. Leisure-time vigorous physical activity is associated with better lung function: the prospective ECRHS study, Thorax. 2018;73 (4):376-384.

8. Carsin AE, Fuertes E, Schaffner E et al. Restrictive spirometry pattern is associated with low physical activity levels. A population based international study. Respir Med. 2019;146:116-123.

9. Burney PG, Luczynska C, Chinn S et al. The European Community Respiratory Health Survey, Eur. Respir. J. 1994;7(5):954-960. 
10. Ackermann-Liebrich U, Kuna-Dibbert B, Probst-Hensch N et al. Follow-up of the Swiss cohort study on Air pollution and lung diseases in adults (SAPALDIA 2) 1991- 2003: methods and characterization of participants, Sozial-Präventivmed. 2005;50(4):245-263.

11. Marcon A, Locatelli F, Keidel D, et al. Airway responsiveness to methacholine and incidence of COPD: an international prospective cohort study. Thorax. 2018;73(9):825-832.

12. Miller MR, Hankinson JA, Brusasco V et al. Standardisation of spirometry, Eur. Respir. J. 2005;26(2):319-338.

13. Bridevaux PO, Dupuis-Lozeron E, Schindler C et al. Spirometer replacement and serial lung function measurements in population studies: results from the SAPALDIA study, Am. J. Epidemiol. 2015;18(10):752-761.

14. Shaaban R, Leynaert B, Soussan D et al. Physical activity and bronchial hyperresponsiveness: European Community Respiratory Health Survey II. Thorax. 2007;62(5):403-10.

15. World Health Organization. www.euro.who.int/en/healthtopics/diseaseprevention/nutrition/a-healthy-lifestyle/body-mass-index-bmi. Date last accessed June $6^{\text {th }} 2019$.

16. Quanjer PH, Stanojevic S, Cole TJ et al. Stocks and ERS Global Lung Function Initiative, Multi-ethnic reference values for spirometry for the 3-95 yr age range: the global lung function 2012 equations, Eur. Respir. J. 2012;40(6):1324-1343.

17. Sperandio ES, Arantes RL, Matheus AC et al. Restrictive pattern on spirometry: association with cardiovascular risk and level of physical activity in asymptomatic adults, J. Bras. Pneumol. 2016;42(1):22-28. 
18. Garcia-Aymerich J, Lange P, Benet M et al. Regular physical activity modifies smoking-related lung function decline and reduces risk of chronic obstructive pulmonary disease: a population-based cohort study. Am J Respir Crit Care Med 2007;175(5):458-63.

19. Moualla M, Qualls C, Arynchyn A et al. Rapid decline in lung function is temporally associated with greater metabolically active adiposity in a longitudinal study of healthy adults. Thorax. 2017;72(12):1113-1120.

20. Peralta GP, Fuertes E, Granell R et al. Childhood body composition trajectories and adolescent lung function: Findings from the ALSPAC study. Am J Respir Crit Care Med. 2019; 200(1):75-83.

21. Gleeson M, Bishop NC, Stensel DJ et al. The anti-inflammatory effects of exercise: mechanisms and implications for the prevention and treatment of disease. Nat Rev Immunol. 2011;11(9):607-15.

22. Aronson D, Roterman I, Yigla M et al. Inverse association between pulmonary function and C-reactive protein in apparently healthy subjects. Am J Respir Crit Care Med. 2006;174(6):626-632.

23. Mannino DM, Ford ES and Redd SC. Obstructive and restrictive lung disease and markers of inflammation: data from the third national health and nutrition examination. Am J Med. 2003;114(9):758-762.

24. Thyagarajan B, Jacobs DR, Apostol GG et al. Plasma fibrinogen and lung function: the CARDIA Study. Int J Epidemiol. 2006;35(4):1001-1008.

25. Singer K and Lumeng CN. The initiation of metabolic inflammation in childhood obesity. J Clin Invest. 2017;127(1):65-73.

26. Marcon A, Accordini S, de Marco R. Adjustment for baseline value in the analysis of change in $\mathrm{FEV}_{1}$ over time. J Allergy Clin Immunol. 2009;124(5):1120. 
Table 1. Participant Characteristics at Baseline by Spirometry Pattern at Follow-up, ECRHS and SAPALDIA, Europe 2001-2011

\begin{tabular}{|c|c|c|c|c|c|c|c|}
\hline \multirow[b]{3}{*}{ Baseline characteristics } & \multicolumn{7}{|c|}{ Spirometry at Follow-up } \\
\hline & \multicolumn{3}{|c|}{ Normal } & \multicolumn{4}{|c|}{ Restrictive } \\
\hline & No. & $\%$ & Mean (SD) & No. & $\%$ & Mean (SD) & $P^{a}$ \\
\hline Sex, Female & \multicolumn{2}{|c|}{$2,58550.5 \%$} & \multicolumn{4}{|c|}{$10057.8 \%$} & 0.058 \\
\hline Age & & & \multirow[t]{2}{*}{$46.57(9.70)$} & & \multicolumn{2}{|r|}{$47.12(10.38)$} & 0.494 \\
\hline BMI & & & & & & & $<0.001$ \\
\hline Underweight & 59 & $1.2 \%$ & & 3 & $1.7 \%$ & & \\
\hline Normal & 2,5555 & $0.0 \%$ & & 593 & $4.1 \%$ & & \\
\hline Overweight & 1,8763 & $6.7 \%$ & & 734 & $2.2 \%$ & & \\
\hline Obese & 6151 & $2.0 \%$ & & 382 & $2.0 \%$ & & \\
\hline BMI change ${ }^{b}$ & & & $1.08(2.13)$ & & & $2.12(2.96)$ & $<0.001$ \\
\hline Smoking status & & & & & & & 0.328 \\
\hline Never smoker & 2,3564 & $6.2 \%$ & & 764 & $3.9 \%$ & & \\
\hline Ex-smoker & 1,6153 & $1.7 \%$ & & 502 & $8.9 \%$ & & \\
\hline Smoker & 1,1462 & $2.4 \%$ & & 472 & $7.2 \%$ & & \\
\hline Pack-year $^{c}$ & $0.25(($ & -13) & & 0.15( & -17) & & 0.464 \\
\hline Exposed to passive smoking (last $12 \mathrm{mo}$ ) & 1,4942 & $9.3 \%$ & & 623 & $5.8 \%$ & & 0.062 \\
\hline Education & & & & & & & 0.131 \\
\hline Low & 221 & $8.5 \%$ & & 141 & $3.9 \%$ & & \\
\hline Medium & 8603 & $3.0 \%$ & & 282 & $7.7 \%$ & & \\
\hline High & 1,5265 & $8.5 \%$ & & 595 & $8.4 \%$ & & \\
\hline \multicolumn{8}{|l|}{ Respiratory symptoms } \\
\hline Had an attack of asthma (last $12 \mathrm{mo}$ ) & 99 & $1.9 \%$ & & 9 & $5.2 \%$ & & 0.003 \\
\hline Wheezing/whistling (last 12 mo) & 6961 & $3.6 \%$ & & 402 & $3.1 \%$ & & $<0.001$ \\
\hline Woken with tight chest (last $12 \mathrm{mo}$ ) & 5411 & $0.6 \%$ & & 331 & $9.1 \%$ & & $<0.001$ \\
\hline Woken by attack of SOB (last $12 \mathrm{mo}$ ) & 234 & $4.6 \%$ & & 10 & $5.8 \%$ & & 0.458 \\
\hline Woken by attack of coughing (last $12 \mathrm{mo}$ ) & 1,2872 & $5.2 \%$ & & 512 & $9.5 \%$ & & 0.198 \\
\hline Chronic cough $^{\mathrm{d}}$ & 237 & $4.6 \%$ & & 14 & $8.1 \%$ & & 0.036 \\
\hline Avoid vigorous exercise (last $12 \mathrm{mo})^{\mathrm{e}}$ & 78 & $1.5 \%$ & & 6 & $3.5 \%$ & & 0.043 \\
\hline \multicolumn{8}{|l|}{ Ever had the following conditions: } \\
\hline Doctor diagnosed asthma & 384 & $7.5 \%$ & & 191 & $1.0 \%$ & & 0.090 \\
\hline Chronic bronchitis $^{\mathrm{f}}$ & 6581 & $2.9 \%$ & & 261 & $5.0 \%$ & & 0.403 \\
\hline Hypertension & 5781 & $3.6 \%$ & & 342 & $5.8 \%$ & & $<0.001$ \\
\hline Heart Disease & 221 & $5.2 \%$ & & 10 & $7.5 \%$ & & 0.243 \\
\hline Depression & 334 & $7.8 \%$ & & 12 & $9.0 \%$ & & 0.629 \\
\hline Diabetes & 158 & $3.7 \%$ & & 6 & $4.5 \%$ & & 0.640 \\
\hline Cancer & 209 & $4.9 \%$ & & 6 & $4.5 \%$ & & 0.825 \\
\hline Stroke & 113 & $2.6 \%$ & & 3 & $2.2 \%$ & & 0.771 \\
\hline Physically active & 1,8603 & $6.3 \%$ & & 452 & $6.0 \%$ & & 0.005 \\
\hline
\end{tabular}


$\mathrm{FEV}_{1}, \%$ pred

101.93 (10.77)

$88.20(6.07)<0.001$

FVC, \%pred

Study

\section{ECRHS}

SAPALDIA

$2,50749.0 \%$

$7241.6 \%$

ECRHS: European Community Respiratory Health Survey, SAPALDIA: Swiss study on Air Pollution and Lung and Heart Diseases in adults. SD: standard deviation. BMI: Body Mass Index. SOB: shortness of breath. mo: month. FVC: forced vital capacity. $\mathrm{FEV}_{1}$ : forced expiratory volume in the first second. \%pred: percent of predicted value.

${ }^{\text {a }} P$ from chi $^{2}$ test (categorical) and anova (continous).

${ }^{\mathrm{b}} \mathrm{BMI}$ at follow-up - BMI at baseline.

${ }^{c}$ Values are expressed as median (25th, 75th percentile).

${ }^{\mathrm{d}}$ Cough during the day or at night on most days for at least 3 months.

${ }^{\mathrm{e}}$ Avoid taking vigorous exercise because of breathing problems.

${ }^{\mathrm{f}}$ Cough and phlegm during the day or at night on most days for at least 3 months. 
Figure 1. Relative Risk of Restrictive Spirometry Pattern Incidence (Active vs Inactive).

Overall, and Stratified by BMI, Study, Sex and Smoking Status. ECRHS and

SAPALDIA, Europe 2001-2011

Legend:

Relative risk from modified Poisson regression, adjusted for age, sex, BMI, chronic cough, woken by tight chest, avoiding physical activity because of respiratory symptoms and FVC at baseline. Centre was included as random effect.

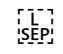

Figure 2. Relative Risk of Restrictive Spirometry Pattern Incidence (Active $v s$ Inactive).

Sensitivity Analyses. ECRHS and SAPALDIA, Europe 2001-2011.

Legend:

RR: Relative risk from modified Poisson regression, adjusted for age, sex, BMI, chronic cough, woken by tight chest, avoiding physical activity because of respiratory symptoms and FVC at baseline. Centre was included as random effect. S1: GLI-equations were used instead of study-specific equations to define spirometry patterns. S2: additionally adjusted for change in BMI between baseline and follow-up. S3: excluding asthmatics. S4: Excluding subjects who avoided physical activity because of their respiratory symptoms. S5: no adjustment for FVC levels at baseline. 


\section{Web Appendix and Web Table}

\section{Regular physical activity levels and incidence of restrictive spirometry pattern: a longitudinal analysis of two population-based cohorts}

Anne-Elie Carsin, Dirk Keidel, Elaine Fuertes, Medea Imboden, Joost Weyler, Dennis Nowak, Joachim Heinrich, Silvia Pascual Erquicia, Jesus Martinez-Moratalla, Ismael Huerta, Jose-Luis Sanchez, Emmanuel Schaffner, Seraina Caviezel, Anna Beckmeyer-Borowko, Chantal Raherison, Isabelle Pin, Pascal Demoly, Bénédicte Leynaert, Isa Cerveri, Guilia Squillacioti, Simone Accordini, Thorarinn Gislason, Cecilie Svanes, Kjell Toren, Bertill Forsberg, Christer Janson, Rain Jogi, Margareta Emtner, Francisco Gómez Real, Debbie Jarvis, Stefano Guerra, Shyamali C Dharmage, Nicole Probst-Hensch, Judith Garcia-Aymerich

\section{Web Table 1}

Web Appendix 1 
Web Table 1. Participant Characteristics at Baseline by Baseline Physical Activity, ECRHS and SAPALDIA, Europe 2001-2011

\begin{tabular}{|c|c|c|c|c|c|}
\hline \multirow[b]{3}{*}{ Baseline characteristics } & \multicolumn{5}{|c|}{ Physical Activity at baseline } \\
\hline & \multicolumn{2}{|c|}{ Non-active } & \multicolumn{3}{|c|}{ Active } \\
\hline & No. & Mean (SD) & No. & Mean (SD) & $P^{a}$ \\
\hline Sex, Female & $1,79853.1 \%$ & & $88746.6 \%$ & & $<0.001$ \\
\hline Age & & $47.3(9.9)$ & & $45.4(9.4)$ & $<0.001$ \\
\hline BMI & & & & & $<0.001$ \\
\hline Underweight & $52 \quad 1.5 \%$ & & $10 \quad 0.5 \%$ & & \\
\hline Normal & $1,62948.2 \%$ & & $98551.9 \%$ & & \\
\hline Overweight & $1,23636.6 \%$ & & $71337.6 \%$ & & \\
\hline Obese & $46413.7 \%$ & & $18910.0 \%$ & & \\
\hline BMI change ${ }^{b}$ & & $1.1(2.2)$ & & $1.1(2.1)$ & 0.253 \\
\hline Smoking status & & & & & 0.017 \\
\hline Never smoker & $1,53645.4 \%$ & & $89647.1 \%$ & & \\
\hline Ex-smoker & $1,04530.9 \%$ & & $62032.6 \%$ & & \\
\hline Smoker & $80523.8 \%$ & & $38820.4 \%$ & & \\
\hline Pack-year ${ }^{c}$ & $1.9(0-18)$ & & $0.6(0-14)$ & & 0.464 \\
\hline Exposed to passive smoking (last $12 \mathrm{mo}$ ) & $1,03630.6 \%$ & & $52027.4 \%$ & & 0.013 \\
\hline Education & & & & & 0.001 \\
\hline Low & $17010.3 \%$ & & $65 \quad 6.2 \%$ & & \\
\hline Medium & $54532.9 \%$ & & $34332.6 \%$ & & \\
\hline High & $94056.8 \%$ & & $64561.3 \%$ & & \\
\hline \multicolumn{6}{|l|}{ Respiratory symptoms } \\
\hline Had an attack of asthma (last $12 \mathrm{mo}$ ) & $70 \quad 2.1 \%$ & & $38 \quad 2.0 \%$ & & 0.865 \\
\hline Wheezing/whistling (last 12 mo) & $48514.3 \%$ & & $25113.2 \%$ & & 0.253 \\
\hline Woken with tight chest (last $12 \mathrm{mo}$ ) & $38911.5 \%$ & & $185 \quad 9.7 \%$ & & 0.047 \\
\hline Woken by attack of SOB (last $12 \mathrm{mo}$ ) & $1614.8 \%$ & & $83 \quad 4.4 \%$ & & 0.514 \\
\hline Woken by attack of coughing (last $12 \mathrm{mo}$ ) & $87625.9 \%$ & & $46224.3 \%$ & & 0.195 \\
\hline Chronic cough $^{\mathrm{d}}$ & $1765.2 \%$ & & $75 \quad 4.0 \%$ & & 0.040 \\
\hline Avoid vigorous exercise (last $12 \mathrm{mo})^{\mathrm{e}}$ & $58 \quad 1.7 \%$ & & $26 \quad 1.4 \%$ & & 0.333 \\
\hline \multicolumn{6}{|l|}{ Ever had the following conditions: } \\
\hline Doctor diagnosed asthma & $2677.9 \%$ & & $1367.2 \%$ & & 0.335 \\
\hline Chronic bronchitis $^{\mathrm{f}}$ & $46813.8 \%$ & & $21611.3 \%$ & & 0.010 \\
\hline Hypertension & $43915.5 \%$ & & $17311.2 \%$ & & $<0.001$ \\
\hline Heart Disease & $1535.4 \%$ & & $78 \quad 5.0 \%$ & & 0.641 \\
\hline Depression & $236 \quad 8.3 \%$ & & $110 \quad 7.1 \%$ & & 0.159 \\
\hline Diabetes & $117 \quad 4.1 \%$ & & $47 \quad 3.0 \%$ & & 0.070 \\
\hline Cancer & $159 \quad 5.6 \%$ & & $56 \quad 3.6 \%$ & & 0.004 \\
\hline Stroke & $81 \quad 2.8 \%$ & & $35 \quad 2.3 \%$ & & 0.247 \\
\hline $\mathrm{FEV}_{1}, \%$ pred & & 102.8 (11.7) & & $103.2(11.4)$ & 0.262 \\
\hline
\end{tabular}


Study

ECRHS

SAPALDIA
$1,66049.0 \%$

$1,72851.0 \%$
$1,05455.3 \%$

$85144.7 \%$

ECRHS: European Community Respiratory Health Survey, SAPALDIA: Swiss study on Air Pollution and Lung and Heart Diseases in adults. SD: standard deviation. BMI: Body Mass Index. SOB: shortness of breath. mo: month. FVC: forced vital capacity. $\mathrm{FEV}_{1}$ : forced expiratory volume in the first second. \%pred: percent of predicted value.

a $P$ from chi $^{2}$ test (categorical) and anova (continous).

${ }^{\mathrm{b}} \mathrm{BMI}$ at follow-up - BMI at baseline.

${ }^{c}$ Values are expressed as median (25th, 75th percentile).

${ }^{d}$ Cough during the day or at night on most days for at least 3 months.

${ }^{\mathrm{e}}$ Avoid taking vigorous exercise because of breathing problems.

${ }^{f}$ Cough and phlegm during the day or at night on most days for at least 3 months. 
Web Appendix 1: Funding agencies for the European Community Respiratory Health Survey

\section{Financial Support for ECRHS II}

Belgium: Antwerp: Fund for Scientific Research (grant code, G.0402.00), University of Antwerp, Flemish Health Ministry; Estonia: Tartu Estonian Science Foundation grant no 4350; France: (All) Programme Hospitalier de Recherche Clinique-Direction de la Recherche Clinique (DRC) de Grenoble 2000 number 2610, Ministry of Health, Ministère de l'Emploi et de la Solidarité, Direction Génerale de la Santé, Centre Hospitalier Universitaire (CHU) de Grenoble, Bordeaux: Institut Pneumologique d'Aquitaine, Grenoble: Comite des Maladies Respiratoires de l'Isere, Montpellier: Aventis ( France), Direction Regionale des Affaires Sanitaires et Sociales LanguedocRoussillon, Paris: Union Chimique Belge- Pharma (France), Aventis (France), Glaxo France; Germany: Erfurt GSF_-National Research Centre for Environment and Health, Deutsche Forschungsgemeinschaft (grant code, FR1526/1-1), Hamburg: GSFNational Research Centre for Environment and Health, Deutsche Forschungsgemeinschaft (grant code, MA 711/4-1); Iceland: Reykjavik, Icelandic Research Council, Icelandic University Hospital Fund; Italy: Pavia GlaxoSmithKline Italy, Italian Ministry of University and Scientific and Technological Research (MURST), Local University Funding for Research 1998 and 1999; Norway: Bergen: Norwegian Research Council, Norwegian Asthma and Allergy Association, Glaxo Wellcome AS, Norway Research Fund; Spain: Fondo de Investigacion Santarias (grant codes, 97/0035-01,99/0034-01 and 99/0034 02), Hospital Universitario de Albacete, Consejeria de Sanidad, Barcelona: Sociedad Espanola de Neumología y Cirugía Toracica, Public Health Service (grant code, R01 HL62633-01), Fondo de Investigaciones Santarias (grant codes, 97/0035-01, 99/0034-01, and 99/0034-02), Consell Interdepartamentalde Recerca i Innovació Tecnològica (grant code, 1999SGR 00241) Instituto de Salud Carlos III; Red de Centros de Epidemiología y Salud Pública, C03/09, Red de Bases moleculares y fisiológicas de las Enfermedades Respiratorias,C03/011 and Red de Grupos Infancia y Medio Ambiente G03/176, Huelva: Fondo de Investigaciones Santarias (grant codes, 97/0035-01, 99/0034-01, and 99/003402), Galdakao: Basque Health Department, Oviedo: Fondo de Investigaciones Sanitaria (97/0035-02, 97/0035, 99/0034-01, 99/0034-02, 99/0034-04, 99/0034-06, 99/350, 99/0034--07), European Commission (EU-PEAL PL01237), Generalitat de Catalunya (CIRIT 1999 SGR 00214), Hospital Universitario de Albacete, Sociedad Española de Neumología y Cirugía Torácica (SEPAR R01 HL62633-01) Red de Centros de Epidemiología y Salud Pública (C03/09), Red de Bases moleculares y fisiológicas de las Enfermedades Respiratorias (C03/011) and Red de Grupos Infancia y Medio Ambiente (G03/176); 97/0035-01, 99/0034-01, and 99/0034-02); Sweden: Göteborg, Umea, Uppsala: Swedish Heart Lung Foundation, Swedish Foundation for Health Care Sciences and Allergy Research, Swedish Asthma and Allergy Foundation, Swedish Cancer and Allergy Foundation, Swedish Council for Working Life and Social Research (FAS); Switzerland: Basel Swiss National Science Foundation, Swiss Federal Office for Education and Science, Swiss National Accident Insurance Fund; UK: Ipswich and 
Norwich: Asthma UK (formerly known as National Asthma Campaign). Cordination: The coordination of this work was supported by the European Commission, as part of their Quality of Life programme, (Grant code: QLK4-CT-1999-01237).

\section{Financial Support for ECRHS III}

Belgium: Antwerp South, Antwerp City: Research Foundation Flanders (FWO), grant code G.0.410.08.N.10 (both sites); Estonia: Tartu- SF0180060s09 from the Estonian Ministry of Education; France: (All) Ministère de la Santé. Programme Hospitalier de Recherche Clinique (PHRC) national 2010, Bordeaux: INSERM U897 Université Bordeaux segalen, Grenoble: Comite Scientifique AGIRadom 2011, Paris: Agence Nationale de la Santé, Région Ile de France, domaine d'intérêt majeur (DIM); Germany: Erfurt: German Research Foundation HE 3294/10-1, Hamburg: German Research Foundation MA 711/6-1, NO 262/7-1; Iceland: Reykjavik: The Landspitali University Hospital Research Fund, University of Iceland Research Fund, ResMed Foundation, California, USA, Orkuveita Reykjavikur (Geothermal plant), Vegagerðin (The Icelandic Road Administration (ICERA); Italy: All Italian centres were funded by the Italian Ministry of Health, Chiesi Farmaceutici SpA. Norway: Norwegian Research council grant no 214123, Western Norway Regional Health Authorities grant no 911631, Bergen Medical Research Foundation; Spain: Fondo de Investigación Sanitaria (PS09/02457, PS09/00716 09/01511) PS09/02185 PS09/03190), Servicio Andaluz de Salud, Sociedad Española de Neumología y Cirurgía Torácica (SEPAR 1001/2010), Barcelona: Fondo de Investigación Sanitaria (FIS PS09/00716), Galdakao: Fondo de Investigación Sanitaria (FIS 09/01511), Huelva: Fondo de Investigación Sanitaria (FIS PS09/02185) and Servicio Andaluz de Salud, Oviedo: Fondo de Investigación Sanitaria (FIS PS09/03190) ; Sweden: All centres were funded by The Swedish Heart and Lung Foundation, The Swedish Asthma and Allergy Association, The Swedish Association against Lung and Heart Disease, Swedish Research Council for health, working life and welfare (FORTE), Göteborg: also received further funding from the Swedish Council for Working life and Social Research, Umea: also received funding from Vasterbotten Country Council ALF grant; Switzerland: The Swiss National Science Foundation (grants no 33CSCO-134276/1, 33CSCO-108796, 3247BO-104283, 3247BO-104288, 3247BO-104284, 3247-065896, 3100-059302, 3200-052720, 3200-042532, 4026028099) The Federal office for forest, environment and landscape, The Federal Office of Public Health, The Federal Office of Roads and Transport, the canton's government of Aargan, Basel-Stadt, Basel-Land, Geneva, Luzern, Ticino, Valais and Zürich, the Swiss Lung League, the canton's Lung League of Basel Stadt/ Basel, Landschaft, Geneva, Ticino, Valais and Zurich, SUVA, Freiwillige Akademische Gesellschaft, UBS Wealth Foundation, Talecris Biotherapeutics GmbH, Abbott Diagnostics, European Commission 018996 (GABRIEL), Wellcome Trust WT 084703MA, United Kingdom: Medical Research Council (Grant Number 92091). Support also provided by the National Institute for Health Research through the Primary Care Research Network. 


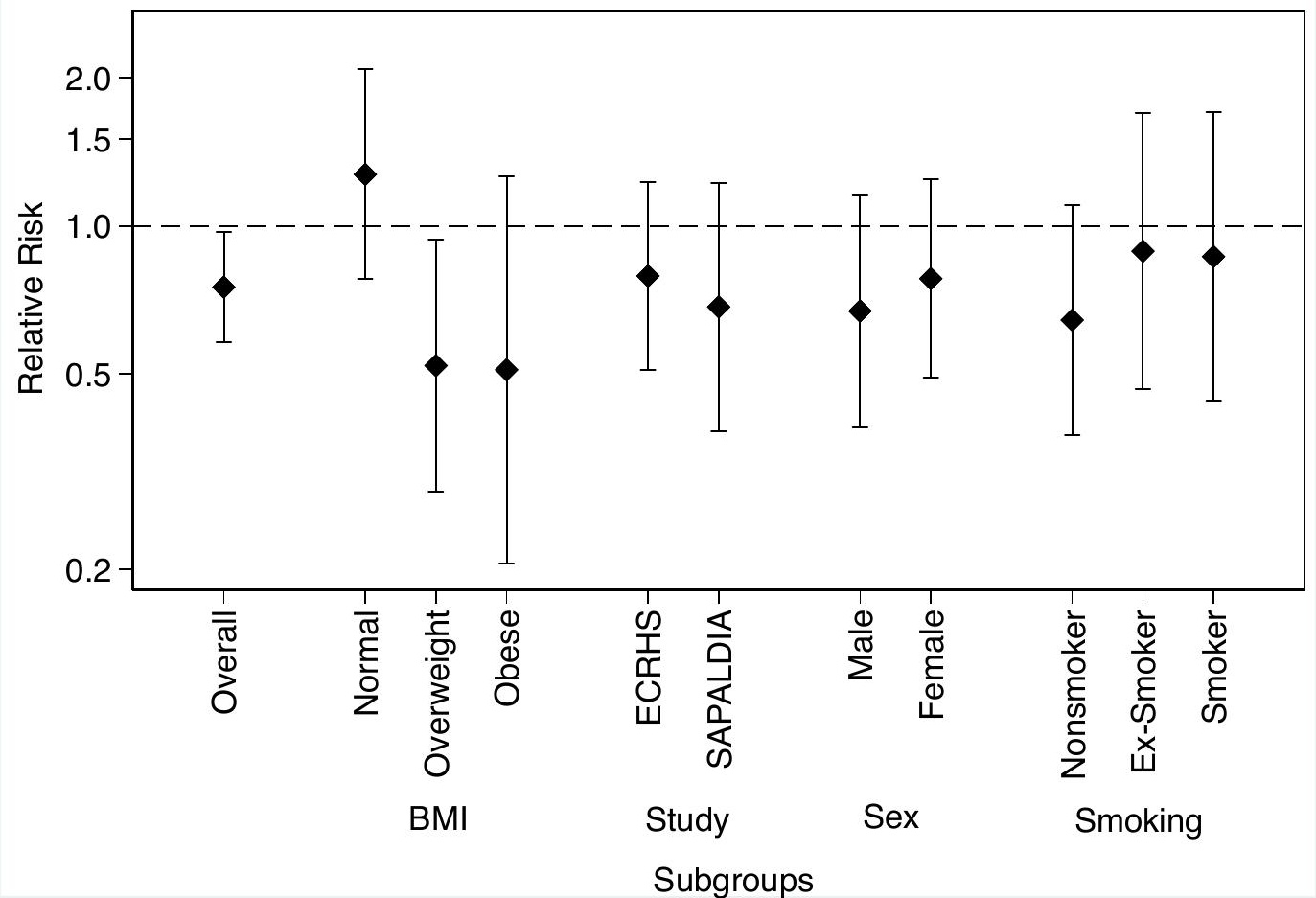




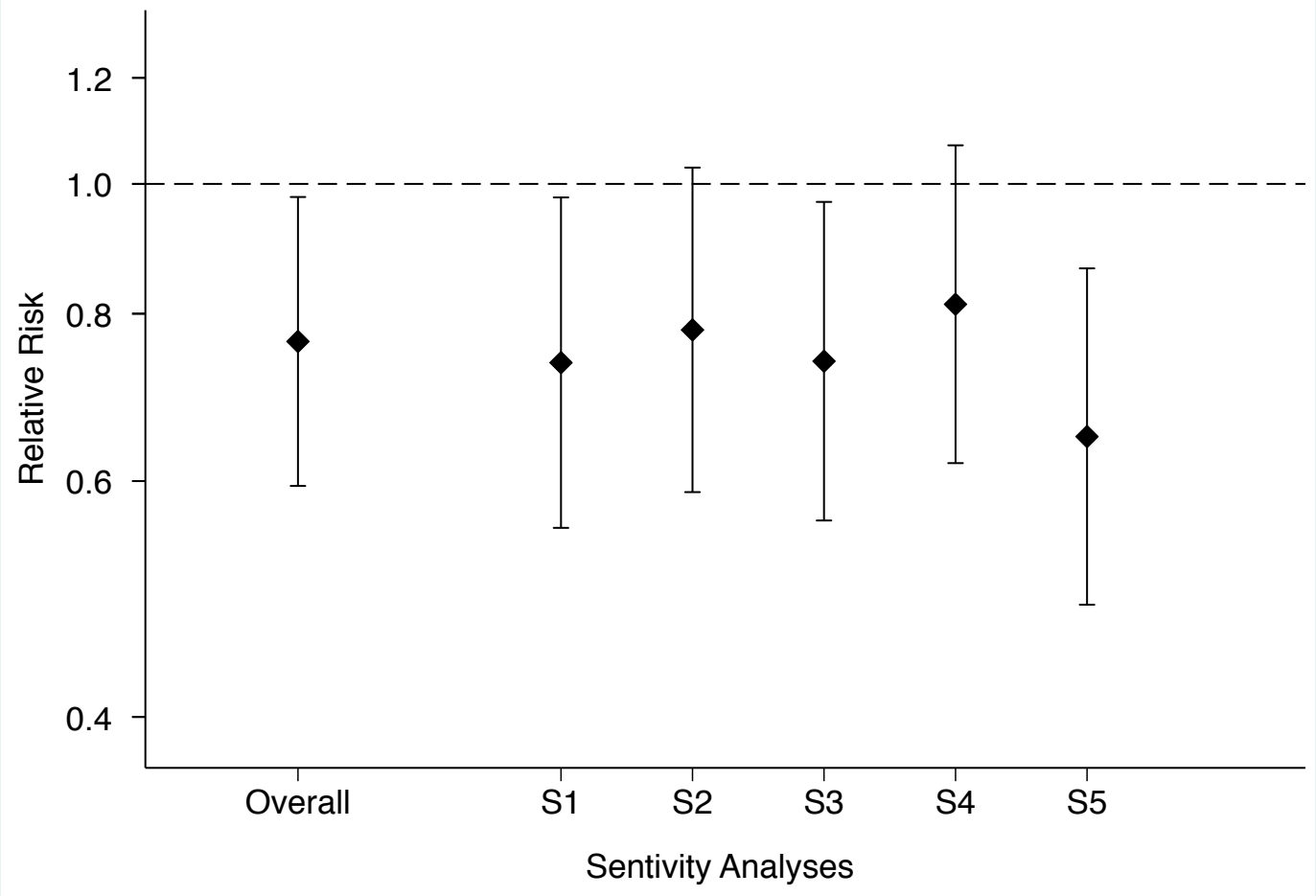

